II Congreso Internacional Estéticas Híbridas de la Imagen en Movimiento: Identidad y Patrimonio

20 -22 octubre 2021. Universitat Politècnica de València

Doi: https://doi.org/10.4995/EShID2021.2021.13236

\title{
ENSAYISTAS: cartografías de la experimentación y las experiencias fílmicas
}

\section{Sergio Martín ${ }^{1}$}

${ }^{1}$ Universitat Politècnica de València, serma10s@bbaa.upv.es

\begin{abstract}
The filmic essay has long been subordinated as a distillation of other genres such as documentaries or literature. Despite the fact that this has laid the foundations on which to begin to analyze these formats, others have erred in forgetting the audiovisual character compared to the literary heritage (Lopate, 2007). For this reason, it is necessary to rethink the nature of this category, which exceeds the classical typologies due to its capacity for experimentation in forms, as well as its plastic malleability when working with moving images. This fact is reflected in how it fluctuates narratologically between fiction, non-fiction and experimentation (Weinrichter, 2007). The critic André Bazin has been considered one of the first to speak of the possibility of the essayistic in the cinema (García, 2006), an idea similar to the caméra-stylo proposed by Alexandre Astruc (Rascaroli, 2017) and coinciding with the same turning point: a representation of the author's ability to represent himself in favor of an intimate and personal proposal.
\end{abstract}

That is why, in its own hybrid capacity, it is known as a hyper-gender (Catala, 2005) capable of exploring the complexities of the rhizomatic relationships of thought, through the videographic record (Rodriguez, 2011), when facing to the decisions of structuring the videos (Amiel, 2005). On the other hand, this is possible due to its unsystematic nature, which provokes dialectical encounters that single out the discontinuities and, thus, are unified through the ruptures that open up in the assembly process (Provitina, 2014). Thus, this device has proven to be a critical tool, heretical of thought (Adorno, 2003), which does not allow itself to be dogmatized when facing the act of mapping the different visual economies, which are usually based on personal experiences and their link with their cultural contexts.

Thus, this communication tries to bring together what would be considered an audiovisual essay and how it would work by exploring the identities reflected on the montage. For this, different proposals that delve into these paradigms of discursive and formal experimentation will be taken as a starting point. Therefore, this analysis will be carried out through pieces that move between video art and the cinematographic practice of authors such as Dara Birnbaum, María Cañas, the O.R.G.I.A. or Maya Deren. 
ENSAYISTAS: cartografías de la experimentación y las experiencias filmicas

Keywords: film-essay, vídeo, cinema, image, assembly

\section{Resumen}

El ensayo fílmico ha sido largamente subordinado como un destilado de otros géneros como el documental o la literatura. A pesar de que ello ha sentado las bases sobre las que comenzar a analizar estos formatos, otros han errado en olvidar el carácter audiovisual frente a la herencia literaria (Lopate, 2007). Por este motivo, cabe repensar la naturaleza de esta categoría, la cual excede las tipologías clásicas por su capacidad de experimentación en las formas, así como su maleabilidad plástica a la hora de trabajar con las imágenes en movimiento. Este hecho se refleja en cómo fluctúa narratológicamente entre la ficción, la no-ficción y la experimentación (Weinrichter, 2007). Al crítico André Bazin se le ha considerado uno de los primeros en hablar de la posibilidad de lo ensayístico en el cine (García, 2006), idea pareja a la caméra-stylo que proponía Alexandre Astruc (Rascaroli, 2017) y coincidiendo en el mismo punto de inflexión: una representación de la capacidad del autor de representarse en pro de una propuesta íntima y de corte personal.

Es por ello, que en su propia capacidad híbrida se le conozca como un hiper-género (Catala, 2005) capaz de explorar las complejidades de las relaciones rizomáticas del pensamiento, mediante el registro videográfico (Rodriguez, 2011), a la hora de enfrentarse a las decisiones de estructuración de los vídeos (Amiel, 2005). Por otro lado, esto es posible debido a su carácter asistemático, lo que provoca encuentros dialécticos que singularizan las discontinuidades $y$, de ese modo, se unifican mediante las rupturas que se abren en el proceso del montaje (Provitina, 2014). Así pues, este dispositivo ha demostrado ser una herramienta crítica, hereje del pensamiento (Adorno, 2003), que no se deja dogmatizar a la hora de enfrentarse al acto de cartografiar las diferentes economías visuales, las cuales suelen basarse en las experiencias personales y su vinculación con sus contextos culturales.

Así pues, esta comunicación trata de acercar qué se consideraría un ensayo audiovisual y cómo funcionaría mediante la exploración de las identidades reflejadas sobre el montaje. Para ello, se tomarán como punto de partida diferentes propuestas que ahonden en estos paradigmas de la experimentación discursiva y formal. Por ende, este análisis se llevará a cabo a través de piezas que se mueven entre el videoarte y la práctica cinematográfica de autoras como Dara Birnbaum, María Cañas, el colectivo O.R.G.I.A. o Maya Deren.

Palabras clave: ensayo audiovisual, vídeo, cine, imagen, montaje 
Sergio Martín

\section{Introducción: una performatividad del pensamiento}

Miles de horas montadas a través de imágenes y sonidos que buscan crear su propia realidad, incontables horas de esfuerzo puestas en concebir y cuestionar un orden imperante. La producción ensayística persigue la posibilidad de la incertidumbre del conocimiento que las instituciones socio-políticas tratan de regular. Este es uno de los principales motivos por los que el ensayo ha ido creciendo en popularidad en una etapa definida por las crisis de representación. No obstante, ¿qué es?, ¿cómo está siendo?, ¿cuál es la relevancia de algo tan específico y a la vez tan escurridizo?

Dicho interés tiene varios puntos de arranque sobre los cuales se ha tratado de cimentar, sin éxito, una explicación que fosilizase la estructura del ensayo. Por ello, esta forma es una de las herramientas más versátiles en la investigación interdisciplinar, forzando al resto de saberes hegemónicos a cuestionarse su naturaleza, así como su vinculación con el exterior. Este implica una lectura a múltiples capas sobre la producción de conocimiento y su posterior registro, ¿cómo se están creando otros puntos de vista?

"Exagium" es en latín la forma de señalar algo pesado, lo que más adelante se usó para referirse metafóricamente al acto de sopesar una idea. Esa puesta en común se lleva a cabo como una prueba sin una conclusión científica, solo busca aproximarse a sus zonas liminales. Tal y como describe el escritor francés Montaigne en el s. XVI, el ensayo le permite observar y discernir una materia auscultando la profundidad de sus orillas (Provitina, 2014). Por ende, semejante procedimiento explora e interpreta otras vías posibles del conocimiento, abre otros caminos y desplaza el pensamiento hacia otras fronteras. De este modo, lo que se lleva a cabo es una reorganización de la mirada sobre una materia, una relectura crítica que trata de dar otras respuestas mediante el desplazamiento. Estos movimientos se generan a través de un pensamiento asistemático y discontinuo, el resultado de arriesgarse a errar (García, 2006) y mirar de frente al abismo. Por estos motivos, el ensayo como herramienta fomenta la heteroglosia y el dialogismo, moldeando diferentes formas sobre lo existente $y$ experimentando otras vertientes aún no practicadas. Es de este modo como el ensayo audiovisual ha generado tanto debate desde las prácticas artísticas.

No obstante, ¿cómo ha surgido? La forma ensayística dentro del ámbito cinematográfico no tiene un nacimiento claro, para Román Gubern fue con Christensen en Häxan (1922), para Riviette lo fue con Rosellini en Viaggio a Italia (1950) y, el más conocido, para Andrè Bazin sería con Lettre du Siberié (1958) de Chris Marker. Lo interesante de estos ejemplos es que tienen en común es una mirada hacia un mundo en particular desde distintas maneras de abordarlo. No obstante, una de las teorías más sugeridas es que el ensayo audiovisual se destila a raíz del género documental, debido al uso de material de no-ficción relacionado con el registro de la realidad. Este hecho 
por sí mismo podría ser un error, ya que el ensayo se consideraría una representación de algo ya propuesto en común previamente por lo que es un reflejo reflexionado sobre una representación ya construida y no un registro directo. Esta metodología sobre lo ensayístico en lo fílmico podría construir un terreno para sí mismo y que no lo dominen sus paralelismos con el ensayo literario o el género documental cinematográfico. Un caso en este ámbito sería la denominación de hiper-género que propone Josep M. Català, definiendo que más que un género es una categoría que fluctúa entre la experimentación, la no-ficción y la ficción (2005), dando como resultado una forma que piensa el medio audiovisual mediante una estructura discontinua que trata de no encerrarse en sí misma ni hacerlo con las ideas que replantea fluyendo hacia otros destinos epistemológicos.

En esta línea, la figura de autor es otro de los factores más discutidos dentro de este campo debido a que se considera una de sus características fundacionales (Català, 2014). Este fenómeno es indivisible de la forma de actuación del ensayo sobre el material a abordar, ya que la autoría se refleja a través de las decisiones en el proceso de montaje. Por ende, la subjetividad de la producción se observa en la edición que se presenta en las piezas fílmicas, lo que lleva al siguiente punto que debe reivindicarse: la propia esencia audiovisual del ensayo fílmico. Algunos autores han insistido en señalar una supuesta exclusividad de la herencia literaria frente a la experimental de los medios audiovisuales (Lopate, 2007), lo que ocasiona que se pierda cualquier análisis sobre las particularidades de esta última. Esto no permite que el debate se amplíe hacia la producción e investigación artística como vectores de transformación de las formas del ensayo. Por lo tanto, es relevante insistir en que este tipo de prácticas beben ya no solo del universo literario o de las teorías sobre los medios fílmicos sino también de las teorías en torno a las artes y a las imágenes. Es de este modo como se propone analizar en este artículo algunos ejemplos que puedan ser definidos como ensayos o, al menos, como aproximaciones ensayísticas sobre las imágenes. Se trata, en sí, de poder abordar la performatividad de las imágenes (Soto, 2020) o lo que viene a ser el hacer hablar a estas sobre los contextos de actuación posibles que se abren en la flexibilidad e interseccionalidad a través de este formato, tal y como plantea Judith Butler sobre el funcionamiento de su "teoría de la performatividad" a través de la naturalización de otros conceptos a raíz de la anticipación de lo nuevo y un conjunto sostenido de actos que estructuran nuevos hábitos (2018).

La importancia de este giro perfomático es la de poner en disputa los discursos actuales hacia otras maneras de mirar, tanto en la producción ensayística como en la audiovisual. Por lo tanto, a través del presente artículo se propone establecer una cartografía que señale las experiencias de las autoras a través de su experimentación fílmica, recogiendo de este modo casos de estudio que muestren algunos de los elementos desarrollados previamente. Por ello, este recorrido se centra en observar 
cómo desde la práctica artística y la fílmica se han moldeado los fenómenos audiovisuales en favor de la representación de sus propias autoras, de su subjetividad. Ante todo, estos casos se desmenuzarán en favor de sus características como ensayos, aunque estos mismos no hayan sido catalogados como tales; lo que refuerza la idea de lo indomesticable que puede ser tratar de crear una etiqueta del ensayo. Como define Adorno el ensayo se considera una práctica crítica que puede suspenderse en cualquier momento (Adorno, 1962), lo que muestra su capacidad discontinua de congelar y observar con detenimiento el pensamiento puesto en cuestión. Este movimiento favorece una dialéctica de los materiales empleados, tal y como señalaba Hans Richter en uno de los artículos fundacionales sobre el ensayo fílmico en 1949. Esa dialéctica procedería del choque en el proceso de montaje de materiales -o imágenes- en las que se suspende su interpretación a través de sus intersticios (Deleuze, 1987), investigando otras relaciones y planteando una performatividad de nuevos paradigmas. Por lo tanto, dichos formatos brindan la disrupción de las temporalidades canónicas, frenando la contemporaneidad y tejiendo otros diálogos (Moxey, 2015). Se muestran tiempos heterogéneos, tanto históricos como formales, propuestas responden a necesidades aún por explorar.

Sin embargo, estas interrupciones simbólicas que fomenta el ensayo no es un hecho aislado, sino que responde a un contexto determinado que beneficiaron su aparición. Por una parte, lo que Paolo Granata ha denominado como "videomorfosis" (Granata, 2018). Este investigador viene a señalar el cambio del paradigma de la mirada perspectiva por el de la videomorfosis, una transformación debido a los elementos intrínsecos de los fenómenos de las imágenes en movimiento, un cambio en la forma simbólica imperante. En contraposición al punto único, la narración y las sucesiones jerárquicas de la perspectiva, la videomorfosis se presenta como un universo múltiple, fragmentario e irregular. Un pensamiento vinculado hacia las ecologías visuales, a la recopilación y relectura de la contemporaneidad tal y como realizan algunas de las autoras que se comentarán más adelante. Este paradigma híbrido se define con el propósito de atravesar, explorar e interactuar con su entorno más allá de embotellarlo en una definición hermética. Por otra parte, la atmósfera conocida como la muerte del cine o post-cine también ha creado un campo proclive al surgimiento de formatos híbridos como el ensayo. Los cambios tecnológicos y su obsolescencia han generado debates en torno a la conservación y el patrimonio cinematográfico. La aceleración que han sufrido los medios tecnológicos ha mostrado lo efímero de los grandes relatos modernos, cuestionados desde el nacimiento de diferentes formatos audiovisuales como la TV o el vídeo en los años 60. La búsqueda de la especificidad de cada uno de estos medios generó un campo de batalla en el que se plantearon sus particularidades, poniendo en tela de juicio las catalogaciones de género cinematográficas, más propias de una mentalidad positivista y moderna. Esta muerte, en vida, de lo cinematográfico frente a otros programas de empleo de imágenes en movimiento mostraron que no era 
exactamente un fin del medio, sino una mutación. El conocido ensayo de Expanded Cinema (1970) de Gene Youngblood es un claro ejemplo de esta nueva actitud frente a lo audiovisual, centrando la cuestión en dejar de preguntar qué es el cine por cuándo es cine, tal y como propone Thomas Elsaesser (Russo, 2008). Debido a estas metamorfosis los análisis circularon hacia territorios intermediales, lo que se convirtió en el detonante de otra oleada de experimentación artística que criticó a los medios mediante formatos híbridos.

A modo de conclusión de esta introducción, el ensayo audiovisual se muestra como una herramienta que surge de los replanteamientos de las estructuras de los medios siendo una categoría huidiza. Ofrece la posibilidad de que su manejo también produzca obras escurridizas que no se establecen sobre un terreno firme proponiendo que ese movimiento sea el que reconduzca los significados puestos en común. Por este motivo, las obras que se analizarán en el presente escrito se centrarán en el uso de sus imágenes, en la experimentación de su montaje y en su capacidad de desplazar el pensamiento, dejando a un lado las consideraciones históricas de las propias autoras. En el breve espacio de estas palabras, la única misión es la de ampliar las consideraciones del uso ensayístico del universo fílmico y cómo este se incrusta en el tejido artístico como fenómeno crítico que destruye sin romper su propio material. Una actitud enfrentada a una época en la que velocidad anestesia toda capacidad de análisis. Es aquí donde esta categoría se define como una posible actitud iconoclasta, que busca otras verdades tras las imágenes, que explora los continentes desconocidos del conocimiento proponiendo otras hojas de ruta. Los dispositivos que aquí se activan cuestionan el estatus de su propia apropiación, así como sobre el reflejo de las representaciones de las que se adueñan. Estas autoras han tratado de usar su propia experiencia para cuestionar un orden imperante que constriñe lo decible de las imágenes que inundan la cultura visual. Es desde esta simulación documental donde se asoman al vacío y palpan los límites de sus planteamientos, ya que "lo cierto es que, en muchos casos, cuando un artista hace un documental lo que le sale es un ensayo" (Weinrichter, 2007, p. 45)

\section{Experimentación fílmica: el montaje ensayístico en procesión}

Para poder llevar a cabo estos análisis se debe partir de algunos puntos de anclaje para ir discerniendo en la neblina de lo considerado como ensayístico. Aquí es donde puede ser útil lo que Josep M. Català propone como imágenes-ensayo, formas-ensayo y ensayos fílmicos, siendo otros modos de acercarse y entender las estrategias ensayísticas (2014). Una de estas son lo que llama como imágenes-ensayo, tanto estáticas como en movimiento, que producen una descontextualización y una resignificación de su contenido. Por lo tanto, se realiza un desplazamiento en el que la 
imagen se hace simbólica transformándose al contacto con otro entorno. Por otro lado, distinta es la estrategia de las formas-ensayo en la que el protagonismo se lleva a cabo mediante el montaje de imágenes, proponiendo un proceso reflexivo en la disposición de estas y su comunicación entre ellas, sin que por ello toda la película pueda ser considerada un ensayo, por lo que se pueden entender fragmentos reflexivos a través de estas formas. Por último, los ensayos fílmicos en sí mismos serían el conjunto de ambas. Este punto de partida ayuda a abrir la estricta definición de lo ensayístico en aras de un acercamiento audiovisual, por lo que en una película puede haber imágenesensayo o formas-ensayo sin que todo sea considerado un producto ensayístico. Muchas de las obras tienen que ver con propuestas originales que se reflejan en montajes que plantean nuevas miradas sobre lo conocido, como pueden ser las composiciones surrealistas u oníricas, por listar metodologías conocidas en las que predomina la necesidad de ensayar la forma para encontrar nuevos materiales en los que seguir ampliando nuestra visión del mundo. Por ello, a lo largo de los siguientes casos de análisis será importante observar estos fenómenos, ya que en la mayoría no toda la pieza puede ser considerada un ensayo. No obstante, es necesario abrir fronteras y estar atentos a cuando una autora busca romper con una concepción preestablecida culturalmente y se aventura en la novedad del descubrimiento.

El recorrido planteado tendrá un carácter cronológico, sin que esto sea específico de lo que se trata de desarrollar en este escrito. A pesar de ello, la disposición cronológica ayuda a establecer un orden abarcable que centre el discurso en las especificidades ensayísticas, dado que la finalidad de este artículo solo alcanza a observar las particularidades formales de esta categoría, más allá de las necesarias vinculaciones que provocan que una obra surja en un momento específico, como en el caso de Dara Birnbaum. Por ello, se recalca que la cronología aquí es puramente instrumental y que no se pretende alcanzar nada más allá del análisis formal de ciertos elementos llevados a cabo en las obras.

Para empezar, por ende, de un modo cronológico destacaría una autora en particular dentro de lo que se conoció como el New American Cinema: Maya Deren. Esta artista es uno de los principales referentes de las oleadas vanguardistas del cine experimental posterior. Su interés como artista, coreógrafa y escritora ha versado en la experimentación del movimiento. Tanto es así que su interés giraba en torno a las posibilidades del medio cinematográfico para captarlo y reflejarlo, una mirada que le llevó a acercarse a las posibilidades de dicho medio como propuesta artística por lo que sus trabajos más conocidos tratan de proponer las especificidades que las imágenes en movimiento poseen dentro del campo artístico.

En particular, lo que aquí se trae a analizar es su conocida Trilogía de la autorrepresentación, en la que como su título indica son tres obras que se centran en la exploración de su experiencia como sujeto empleando las particularidades del medio 
cinematográfico, realizado en celuloide. La primera de estas fue At Land (1944) en la que la propia Deren protagoniza realizando lo que parece un recorrido en formaensayo. La película es un viaje en la que todo se lleva a cabo a través de ensamblar imágenes teniendo en cuenta la dirección que Deren va recorriendo en los planos, de este modo construye un recorrido solo posible mediante el montaje, es decir, cómo se traslada entre los escenarios solo a través de las concatenaciones de los planos. Esto permite poder estructurar un universo propio que además utiliza para generar imágenes que extrañen el sentido lógico de la realidad, como cuando muestra escenas del oleaje ralentizado o revirtiendo el orden de su desplazamiento. Por ende, toda la pieza es una prueba a punto de la herramienta del cine en un modo ensayístico.

La segunda obra es Meshes of the Afternoon (1945). Esta pieza parece estar influida por el surrealismo traducido en manos de la artista, ya que en esta se observa una ruptura temporal en la que la propia autora, de nuevo como protagonista, se encuentra inmersa en un mundo onírico en el que ella persigue una figura, la cual tiene un espejo por rostro, hasta un punto en el que toma un desvío hacia una casa. Este recorrido se repite varias veces, pero generando en cada una de estas variaciones nuevas Maya Deren que van observando a la siguiente, estructurando una problemática visual de disrupción temporal que da a entender que la anterior prepara a la siguiente. Cabe destacar que amparada por este universo onírico, crea imágenes-ensayo como cuando la llave de la casa se llega a convertir en un cuchillo. Se podría entender con esta estrategia que trata de explorar las posibilidades de la asociación simbólica de los objetos. Los fenómenos que se van sucediendo van creando capas que se superponen al relato. Otros muchos detalles insisten en la intencionalidad de Deren de explorar el medio fílmico a través de planos subjetivos, paralelismos visuales entre objetos o en la banda sonora con música experimental, todo ello centrado en ensalzando el mundo onírico que permea toda la película.

Por último, Ritual in transfigured time (1946) también sigue la línea de sus antecesoras, pero en este caso a través de la idea de lo ritual en lo social, explorando a través de la danza los mecanismos de reunión reflejados en una fiesta que acaba en un jardín. Lo relevante aquí es el modo de representar mediante la danza y la teatralidad algo tan común como una reunión social, pero espaciando los tiempos en los que se realizan los encuentros, generando una sensación coreografiada que va deshilando el comportamiento de los presentes. De nuevo, la banda sonora acecha al relato visual proponiendo una sombra de duda sobre lo que se observa, ya que es amenazadora pero surrealista. Todas las personas presentes en el lugar van más despacio y sus rostros no muestran casi emoción ninguna. No hay diálogo, solo movimiento y gestos junto a congelamientos de la imagen. De este modo, Deren vuelve a emplear las particularidades del cine para proponer escenarios imposibles de realizar mediante otro medio consiguiendo una propuesta que parece tratar de repensar lo registrado. 
Esto pone sobre el camino de lo ensayístico la necesidad de estar abiertos a las interpretaciones sin encasillar a las obras en espacios concretos, como pueda ser el psicoanálisis o la semiótica (Stam, Burgoyne, Flitterman-Lewis, 1992). La teoría fílmica encuentra en el ensayo o en las formas que puedan aparecen ensayísticas un talón de Aquiles de su clásica nomenclatura de géneros. Es así como la experimentación de Deren pone en cuestión la representación y ensaya otros modos de reflejar recursos visuales y narrativos que expandan las posibilidades del conocimiento de la percepción humana.

Eso nos lleva a la siguiente propuesta fílmica, L'Opera Mouffe de Agnès Varda de 1958. En esta pieza la autora trata de plantear su experiencia con el embarazo a través de emociones vividas durante la gestación que no son convencionalmente asumidas en sociedad. Estas fluctúan entre la violencia y el romance, acercando la experiencia a distintos estratos en los que no está auratizado este mismo proceso. Realiza distintas asociaciones visuales, ya que no se emplea ningún diálogo, en el que por ejemplo escarba un repollo, corta y vacía una calabaza o incluso muestra una paloma atrapada dentro de un recipiente transparente. En un mundo en el que la mujer es objetivizada a través de la mirada del hombre en el cine (Mulvey, 1975) el terreno del embarazo se convierte en un conflicto. La complejidad de este implica una red de subjetividades que no son lo tradicionalmente mostrado por el cine. Varda propone aquí poder hablar de esta experiencia sin narcisisimos mediante la representación no realista de este acontecimiento, generando imágenes-ensayo que enturbian lo normativo en favor de una exploración que extraña la idea del embarazo. Por ende, esta necesaria diversidad se genera a raíz del desarrollo ensayístico y experimental que ofrece el entorno audiovisual. Se puede observar mediante el encadenamiento de imágenes que tratan de trazar otro mapa posible para esta experiencia. De este modo, Varda se coloca como ensayista gracias a su modo de concebir y vivir las imágenes en movimiento, así como su capacidad de transmisión mediante el montaje. La autora propone, sin encerrar sus imágenes, abrir el debate hacia otras emociones que se viven en el proceso de embarazo. Todo ello explorando la esencialidad de lo fílmico dándole otra vida, otra forma.

El siguiente tramo de este recorrido viene de la mano del videoarte, otra concepción del estudio audiovisual con el vídeo como dispositivo electromagnético que amplió las posibilidades de explorar a través de un mayor control de postproducción, generando un trabajo más intrínseco a particularizar los métodos artísticos mediante la imagen en movimiento. Uno de estos casos es Technology/Transformation: Wonder Woman (1978-79) de Dara Birnbaum. Esta obra critica la figura de la mujer en TV escogiendo un caso paradigmático de la Cultura Visual del momento como la serie de Wonder Woman. Con este caso, Birnbaum parece tratar de analizar las tensiones subjetivas de la construcción de la mujer en las que esta debía actuar como una superheroína 
encargándose tanto de las tareas internas como externas del hogar. Todo ello sin perder los factores atribuidos a lo femenino, continuando siendo una figura encadenada a las estructuras heteropatriarcales a pesar de ser representada como un sujeto poderoso y con superpoderes.

Esta propuesta se basa en el humor colateral del efecto de repetición radical de los gestos de una escena, pero a la vez exagerando el efecto de la figura de la heroína, un mensaje hacia las mujeres de la exigencia que tenían de aceleración al ocupar un rol tan devorador. Por ende, la mayoría del vídeo se centra en la repetición incesante de como la actriz pasa de la mujer a la superheroína. Un torbellino visual que violenta la mirada y expresa la ansiedad de un modo diferente mediante métodos videográficos de edición. El final de este tampoco lo desaprovecha escribiendo la letra de la canción del programa de TV resaltando la sexualización que se describe en esta. El mensaje a través de estas formas-ensayo que se desarrollan muestra la exigencia sobre la mujer y su sexualización, la pretensión de sujeto activo, pero a la vez supeditada al hombre. A través de los procesos de ensayo visual, Birnbaum crea una crítica de su época, un ente que fluye desde lo documental a lo subjetivo.

En esta misma línea, el grupo artístico de O.R.G.I.A., definidas como un espacio heterotópico y fluctuante, presenta una obra que podría ser considerado un ensayo. Este es un despliegue de humor ácido sobre el machismo imperante en las imágenes del imaginario audiovisual del siglo XX español. En P.N.B. (Producto Nacional Bruto) (2005) se expone un imponente trabajo de apropiación en el que mediante fragmentos de películas y anuncios televisivos hacen una cartografía de la agresión de las estructuras heteropatriarcales hacia la mujer. A lo largo del vídeo se observan ejemplos de cómo se educan a las niñas para ser futuras amas de casa y como estas a su vez deben aprender a llevar las tareas del hogar, todo esto pasando también por escenas en las que la mujer se convierte en la presa del hombre en la calle. El ejercicio de ensayo se ejerce desde las asociaciones puestas en común bajo el mismo dispositivo de la obra, creando lazos entre las imágenes y sus significaciones, sacándolas de su contexto y señalando cómo se ejerce esta violencia desde la educación visual en las que se hacen crecer a las mujeres. Por lo tanto, la dialéctica que se produce en los intersticios de los choques entre planos muestra la carga simbólica de los contextos específicos de cada imagen y cómo han sido empleados para subyugar a la mujer, explorando en esta pieza un intento de acusarlos revirtiendo estos procesos.

Y finalmente, el último ejemplo es un caso en el que ella misma se autodenomina una iconoclasta. La artista María Cañas ha demostrado a lo largo de toda su trayectoria su interés por la cultura popular y las tensiones que se generan en esta, desde la religión, la cultura de masas hasta su propia subjetividad. Dos casos paradigmáticos de su labor como videoartista son Holy Thriller (2011) y Sé villana. (La Sevilla del diablo) (2013). El primer caso son imágenes de fragmentos de procesiones de Semana Santa, tintados de 
granate y con la música de Thriller (1984) de Michael Jackson interpretada por una banda popular. El cruce es directo, esta unión audiovisual produce un efecto ensayístico sobre la pieza que reflexiona sobre el sentimiento religioso y apela a una distancia crítica. En el segundo caso, la artista realiza un documental entremezclando elementos de apropiación en los que crítica la visión de la ciudad de Sevilla como centro turístico que obvia los problemas estructurales socio-económicos que sufre la misma, vendiendo una idea que se aleja de la realidad. De nuevo, el montaje de las imágenes y sus procesos de asociación ejercen un proceso reflexivo que se aleja del documental convencional construyendo otra opinión sobre el estado de la cuestión en la ciudad, resignificándose. De este modo, actúa como una iconoclasta iconódula que trata de mostrar lo real desgarrándolo a través de lo fílmico sin la necesidad de establecer una violencia material. Por este motivo, la violencia solo se ejerce sobre la representación de la ciudad, un camino alternativo desde la práctica artística.

\section{Errando en concluir: la imposibilidad de un cierre}

Recapitulando lo construido anteriormente, se puede tratar de recuperar los hilos que se han ido deshilvanando en los capítulos anteriores. Todos los casos expuestos, a pesar de la brevedad de estos y la necesidad de visionarlos, muestran signos de pensamiento ensayístico. Las distintas autoras han mediado con el formato audiovisual para establecer formas innovadoras que hablasen de sus propias vidas, tanto es así que su propia experimentación fílmica no es indivisible de sus experiencias vitales, las cuales son reflejadas como campo de estudio en sus obras. De este modo, al observar las piezas se comprende el pensamiento que se permite errar para descubrir, que no parte de una ruta preestablecida, sino que se va gestando en sí misma. El proceso, por ende, es clave en la formación tanto de imágenes como de formas que se vinculen con un desarrollo ensayístico. No obstante, esto crea la problemática de cómo discernir, ¿todo puede ser un ensayo? ¿qué requiere una película para considerar que forme parte de esta tendencia? Aún es un paradigma por discernir y evaluar, la mayoría de los autores que se han enfrentado a esta ardua tarea divergen, escogiendo sus propias maneras de comprender la metodología del ensayo en su formato audiovisual. De todos modos, estas tensiones no son más que el reflejo de lo escurridizo que demuestra ser esta categoría, no pudiendo ser fácilmente disecable por las estructuras académicas. La potencia de su propia naturaleza remueve el material empleado y lo devuelve al tejido cultural como dispositivo disruptivo de la cotidianeidad. Es así como el valor de las autoras mencionadas se muestra en su modo de ofrecer otras aproximaciones que ponen en jaque tanto a la teoría fílmica como a los diversos campos de los que parten. Así pues, es imposible poder concluir con algo muy determinado, ya que eso podría ser vacuo. La herejía de la crítica favorece aquí una atmósfera de inquietud que descoloca las estructuras existentes, fomentando una 
revisión de estas. Por lo tanto, estas últimas líneas no pueden más que seguir el trayecto que se escapa a toda captación, pero que no deja de mostrarnos destellos de lucidez que deben ser rastreados. De este modo, a través de estas chispas de luz de las distintas obras, se propone la inseguridad de cuándo se está ante lo ensayístico y cómo este actúa a través del material audiovisual, cómo desplaza el pensamiento volcándolo y mostrando la verdadera norma por hábito: la incertidumbre. No obstante, no lo hace para hacer dudar, sino para dejarnos volver a andar y, así, aprender con nuevos ojos.

\section{Referencias}

ADORNO, T. (1962). Notas de Literatura. Barcelona, España: Ariel.

AMIEL, V. (2005). Estética del montaje. Madrid, España: Abada Editores, S.L.

BUTLER, J. (2018). El género en disputa. El feminismo y la subversión de la identidad. Barcelona, España: Paidós.

CATALÀ, J.M. (2005). Écfrasis y film-ensayo. En: Designis: Publicación de la Federación Latinoamericana de Semiótica ( FELS ), ISSN 1578-4223, №. 7-8, 2005 (Ejemplar dedicado a: Los Formatos de la televisión), págs. 223-235

CATALÀ, J.M. (2014). Estética del ensayo. La forma ensayo, de Montaigne a Godard. València, España: Publicacions de la Universitat de València.

GARCÍA, A. (2006). La imagen que piensa. Hacia una definición del ensayo audiovisual, Comunicación y sociedad, 19(2), 75-105. [Consultado el 7-5-2021] Disponible en: https://core.ac.uk/download/pdf/83560365.pdf

GRANATA, P. (2018). Videomorfosis. El vídeo como forma simbólica. En: Vives-Ferrándiz, L. (Ed.), Síntomas culturales. El legado de Erwin Panofsky (pp. 197-219). Vitoria-Gasteiz, España: Sans Soleil Ediciones.

MOXEY, K. (2015) El tiempo de lo visual. La imagen en la historia. Barcelona, España: Sans Soleil Ediciones.

MULVEY, L. (1975). Visual Pleasure and Narrative Cinema. En: Screen, Autumn Vol 16 No. 3.

LOPATE, P. (2007). A la búsqueda del centauro: el cine-ensayo. En: Weinrichter, A. (Ed.) La forma que piensa: tentativas en torno al cine-ensayo (pp. 66-89). Pamplona, España: Gobierno de Navarra, D.L.

PROVITINA, G. (2014). El cine-ensayo. La mirada que piensa. Buenos Aires, Argentina: la marca editora

RASCAROLI, L. (2017). How the essay film thinks. Oxford, United Kingdom: Oxford Universtiy Press.

RUSSO, E. (2008). Lo viejo y lo nuevo ¿qué es del cine en la era del post-cine? En: La Ferla, J. (comp.), Artes y medios audiovisuales: Un estado de la situación II. Las prácticas mediáticas 
Sergio Martín

pre digitales y post analógicas (pp. 26-35). Buenos Aires, Argentina: Aurelia Rivera, Nueva Librería.

STAM, BURGOYNE, FLITTERMAN-LEWIS. (1992). Nuevos conceptos de la teoría del cine. Estructuralismo, semiótica, narratología, psicoanálisis, intertextualidad. Barcelona, España: Ediciones Paidós Ibérica, S.A. 